\title{
Morfodinâmica da desembocadura da Lagoa do Peixe, litoral sul do Brasil
}

\author{
Venisse SCHOSSLER ${ }^{1}$, Elírio E. TOLDO Jr. ${ }^{2} \&$ Norberto DANI ${ }^{3}$
}

1 Centro Polar e Climático, Instituto de Geociências, Universidade Federal do Rio Grande do Sul. Av. Bento Gonçalves, 9.500, CEP 91.540-000, Porto Alegre, RS, Brasil (venisse.schossler@ufrgs.br).

2 Centro de Estudos Costeiros e Oceânicos, Instituto de Geociências, Universidade Federal do Rio Grande do Sul. Av. Bento Gonçalves, 9.500, CEP 91.540-000, Porto Alegre, RS, Brasil (toldo@ufrgs.br).

3 Departamento de Geodésia, Instituto de Geociências, Universidade Federal do Rio Grande do Sul. Av. Bento Gonçalves, 9500, CEP 91.540-000, Porto Alegre, RS, Brasil (norberto.dani@ufrgs.br).

Recebido em 04/2015. Aceito para publicação em 12/2016.

Versão online publicada em 08/05/2017 (www.pesquisasemgeociencias.ufrgs.br)

\begin{abstract}
Resumo - A morfologia de canais é resultado do ambiente em que se encontram, assim como de todas variáveis físicas atuantes. Se a desembocadura está situada em zonas costeiras, a tendência à instabilidade é amplificada pelo próprio meio. Neste artigo são apresentados os resultados do estudo morfodinâmico do canal de comunicação entre a Lagoa do Peixe e o Oceano Atlântico, localizado no Parque Nacional da Lagoa do Peixe, litoral médio do Rio Grande do Sul, Brasil. Também é medida a variabilidade da linha de praia adjacente ao parque. Com o objetivo de determinar a classificação do canal e sua dinâmica natural, foram utilizados uma série de 47 anos de imagens Landsat (1973 - 2009), dados de precipitação da Agencia Nacional de Águas e equações. A interpretação da série temporal e os cálculos das médias de precipitação permitiram descrever o canal da Lagoa do Peixe como um canal de maré, com mecanismo de assoreamento morfodinâmico influenciado pelo regime de precipitação pluviométrica. Os resultados das equações indicaram como fatores determinantes à sua oclusão o prisma de maré e transporte e deposição sedimentar em frente a desembocadura, associados à deriva litorânea de padrão bidirecional da área de estudo. Sua desembocadura possui caráter intermitente e é instável quanto ao seu posicionamento e geometria. A mobilidade da linha de praia adjacente ao Parque Nacional da Lagoa do Peixe foi verificada pelo método de pontos extremos, pixel a pixel, entre duas imagens Landsat de mesmo mês, uma de 1987 e outra de 2009, sendo constatada erosão ao sul da desembocadura do canal da Lagoa do Peixe e acreção ao norte da mesma.
\end{abstract}

Palavras-chave: canal de maré, precipitação pluviométrica, Landsat, lagunas costeiras, linha de praia.

Abstract - Morphodynamics of the LagoA do Peixe inlet, south coast of BraziL. The inlets morphology is a result of the environment in which they are, as well as all active physical variables. If the mouth is situated in coastal areas, the trend towards instability is amplified by the environment itself. This paper presents the results of a morphodynamic study of the communication inlet between the Lagoa do Peixe and the Atlantic Ocean, located in Lagoa do Peixe National Park, middle coast of Rio Grande do Sul, Brazil. It is also measured the variability of adjacent shoreline to the park. In order to determine the classification of the inlet and its natural dynamics, was used series of 47 years of Landsat images (1973-2009), rainfall data of the National Water Agency and equations. The interpretation of the time series and the calculation of averages precipitation allowed to describe the Lagoa do Peixe inlet as a tidal inlet, with silting morphodynamic mechanism, influenced by the rainfall regime. The results of the equations indicated as key factors to its occlusion tidal prism, sediment transport and deposition in front of the mouth, associated with the longshore bidirectional pattern of the study area. The inlet has intermittent character and is unstable on its position and geometry. The mobility of the adjacent shoreline to the Lagoa do Peixe National Park was verified by the method of extreme points, pixel by pixel, between two Landsat images of the same month, one of 1987 and other of 2009, erosion being found south of the mouth of the Lagoa do Peixe inlet and accretion to the north of it.

Keywords: tidal inlet, precipitation, Landsat, coastal lagoons, shoreline. 


\section{Introdução}

A estabilidade de um canal costeiro sofre grande influência da dinâmica do prisma de maré, energia de ondas incidentes e disponibilidade de sedimentos (Coastal Engineering Manual, 2002). A deposição sedimentar em canais e desembocaduras de lagunas costeiras ocorre, principalmente, pelo fluxo lagunar e agentes de transporte como os ventos e as correntes litorâneas, relacionadas à incidência de ondulações. Canais costeiros estáveis geralmente estão associados a margens rochosas e encontram-se praticamente fixos quanto à sua posição e geometria. A profundidade do canal também pode auxiliar a defini-lo: se profundo, geralmente está localizado sobre sedimentos mais resistentes, logo é estável. Já nos instáveis a base do canal é composta por materiais inconsolidados, com menores profundidades. A estabilidade de canais é também governada pelo grau de equilíbrio entre o fluxo do canal e o fluxo do transporte de sedimentos (Jain et al., 2004).

Haines (2008) apresenta uma classificação de lagoas e lagunas costeiras, de acordo com o comportamento da desembocadura de seus canais. A esses corpos d'água denomina de ICOLLs (Intermittently Coastal Open and Closed Lakes and Lagoons - Lagos e Lagunas Costeiras Intermitentemente Fechados ou Abertos). 0 autor afirma que o nível d'água dos ICCOLs depende completamente da precipitação e da evaporação, bem como esse fator pode ser responsável pela abertura do canal, o que inicia o processo sobre o berma se estendendo até entrar em contato com o oceano. Já os fatores mais comuns para explicar o fechamento de um canal são: transporte e deposição sedimentar pelas correntes de maré, correntes litorâneas e transporte eólico.

A deposição de sedimentos no interior da desembocadura e o crescimento de pontais constituem importantes mecanismos responsáveis pelo assoreamento de um canal. Segundo Bruun (1962), canais lagunares são divididos em três regiões: delta de maré vazante, desembocadura e delta de maré enchente. Sua morfologia é um reflexo à entrada e saída de sedimentos, que envolve, simultaneamente: o prisma de maré, a geometria do canal, suprimento sedimentar, fluxo de energia das ondas incidentes, estratigrafia, declividade da costa e alterações de engenharia (Fitzgerald et al., 2001). 0 gradiente existente entre o mar e a laguna, ocasionado pelos ventos e oscilações no nível do mar, forma correntes de marés proporcionais ao prisma de maré. Se essas correntes são responsáveis pela estabilidade do canal ele é classificado como canal de maré.

O objetivo do presente trabalho é descrever o comportamento morfodinâmico do canal que liga a Lagoa do Peixe (LP) intermitentemente ao Oceano Atlântico, no litoral do Rio Grande do Sul (RS). Essa laguna está localizada no Parque Nacional da Lagoa do Peixe (PNLP), local de rara biodiversidade e de fundamental importância à colônia de pescadores ali estabelecida. Outro propósito desse estudo é a descrição da variação e do perfil altimétrico da linha de praia adjacente ao PNLP. A linha de praia pode ser definida como uma interface física entre a água do mar e o continente (Boak \& Turner, 2005). Sua localização, bem como a orientação em que se encontra, pode fornecer informações sobre o comportamento de estruturas costeiras adjacentes, volume de sedimentos e taxas de mobilidade da praia. Ao longo do tempo, a praia muda de posição devido aos movimentos vertical e horizontal dos sedimentos acumulados ou erodidos na zona litorânea, principalmente devido à natureza dinâmica do nível da água (e.g. ondas, marés, ondas de tempestade, setup, runup, etc).

Haines (2008) salienta a importância e a fragilidade dos ICCOLs perante a ação antrópica, pois quando abertos recebem resíduos e poluentes do mar pelo canal, e quando fechados são "lagos", retendo todos esses resíduos e poluentes em seu ambiente. Além disso, esses ambientes são áreas de troca entre as águas salobras do mar e a água doce, o que possibilita a existência e sobrevivência de espécies únicas. Mais de $50 \%$ dos ICCOLs do NSW da Austrália são abertos mecanicamente quando muito cheios, como ocorre na LP. A abertura mecânica de ICCOLs causa impactos, principalmente, se realizada sem planejamento e estudo do melhor período para tal, pois muda o volume de água, reduzindo os nutrientes necessários à flora $\mathrm{e}$ fauna local, assim como pode diminuir a umidade no entorno do corpo de água. Portanto, o estudo da morfodinâmica do canal da LP e linha de praia adjacente é justificado, pois conhecendo seus mecanismos naturais é possível planejar o manejo e desenvolver políticas que visem minimizar os impactos que a sociedade causa a esse ambiente.

\section{2 Área, materiais e métodos}

\section{1 Área}

A LP está situada paralela à linha de costa, com alinhamento geral SW-NE. Essa laguna é protegida da atividade do Oceano Atlântico pelo sistema deposicional Laguna-Barreira Holocênico IV, constituído por depósitos marinhos, praiais, eóli- 
cos e lagunares, de acordo com classificação proposta por Villwock \& Tomazelli (1995). Sua evolução está relacionada aos eventos de regressão e transgressão do nível do mar ocorridos na Planície Costeira do Rio Grande do Sul (PCRGS), durante seu desenvolvimento.

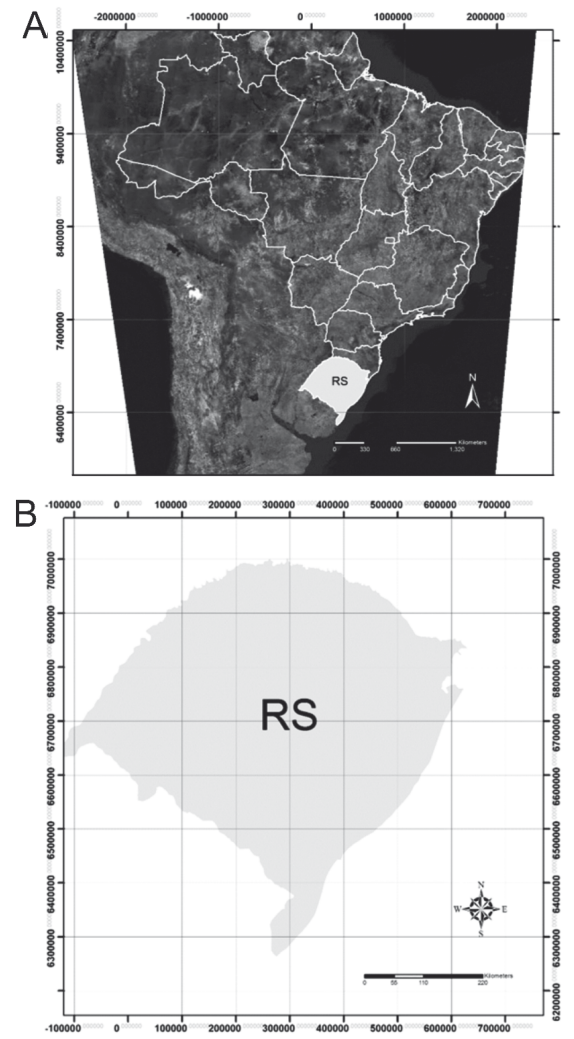

A formação da barreira IV, durante o último evento transgressivo há cinco mil anos, isolou depressões rasas e alongadas no reverso da barreira, ou seja, no contato com a barreira III, onde se instalaram vários corpos lagunares, entre esses a LP (Fig. 1).

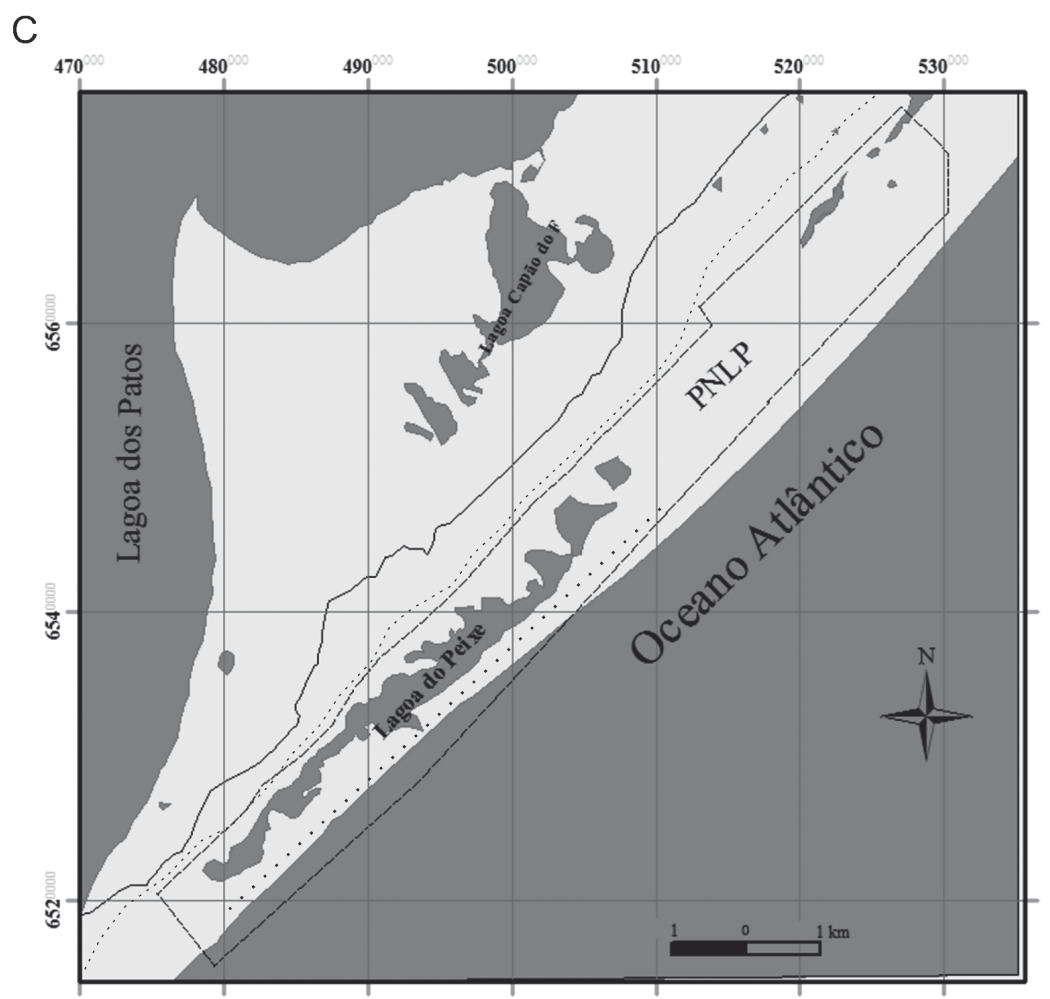

Figura 1. Localização do Parque Nacional da Lagoa do Peixe. A) Localização do estado do Rio Grande do Sul no Brasil; B) Mapa do Rio Grande do Sul; C) Mapa da localização do parque, onde o polígono tracejado corresponde aos limites do parque, a linha tracejada preta indica a localização aproximada do limite entre as barreiras III e IV e a linha pontilhada preta apresenta localização do perfil altimétrico.

Figure 1. Location of National Park of Lagoa do Peixe. A) Rio Grande do Sul location in Brazil; B) Rio Grande do Sul map; C) Park location map, where the dashed polygon corresponds to the park boundaries, the black dashed line indicates the approximate of boundary between the barriers III and IV and the blacked dotted line shows location of altimetry profile.

\subsubsection{Geologia}

Na área da LP a barreira arenosa é bastante estreita. Essa barreira condiciona fisicamente o corpo lagunar, e sua gênese esta associada aos eventos regressivos e transgressivos durante o Pleistoceno e Holoceno, sendo controlada pela topografia anterior (Dillenburg et al., 2000).

Os depósitos no sistema praial são arenosos, compostos por sedimentos quartzosos de granulometria fina ( $\mathrm{Mz}=0,2 \mathrm{~mm}$ ) (Gruber, 2002; Nicolodi et al., 2002). As feições eólicas encontradas na área de estudo são representadas, principalmente, por campos de dunas barcanoides, parabólicas e frontais, as quais são responsáveis pelo significativo volume de sedimentos arenosos transportados pelo vento, da praia para o interior da planície costeira. Arejano (2006) desenvolve estudo sobre a geologia e evolução da LP, com uso de testemunhos, imagens de satélite e fotografias aéreas. Os dados palinológicos indicam que a LP se formou já no Holoceno, há aproximadamente 7.500 anos, e evoluiu pelas variações na espessura de sua lâmina d'água, associadas a fatores climáticos e variações no nível do mar (Knak, 1998). A LP tem sua granulometria bastante homogênea, original da própria praia e do oceano adjacente (lamas a areias finas). De acordo com Arejano (2006), o futuro da LP é ser completamente colmatada, principalmente devido ao transporte eólico. Uma queda do nível do mar aceleraria esse processo, enquanto uma subida do nível do mar poderia retardá-lo. 


\subsubsection{Hidrologia e climatologia}

A laguna possui uma lamina d'água delgada (média de $30 \mathrm{~cm}$ ), com $35 \mathrm{~km}$ de comprimento e largura média de $1 \mathrm{~km}$. Na área de influência do canal pode alcançar $2 \mathrm{~m}$ de profundidade. Em períodos de seca (estiagem) e/ou vazante, é possível observar, nas imagens de satélite, a presença de canais meandrantes no piso lagunar, bem como extensos bancos arenosos construindo ilhas e pontais. Sua hidrodinâmica é fortemente controlada pelo regime de precipitação, uma vez que a laguna não esta associada a uma rede de drenagem, e também não recebe afluência de rios. De acordo com Truccolo (1993), as variações de salinidade são divididas em três porções: norte (limnética), porção do canal da barra (euhalina) e porção centro-sul (mixohalina). 0 clima na área de estudo foi classificado por Nimer (1977) como uma região de clima mesotérmico brando e superúmido, sem presença de uma estação seca, possuindo temperaturas médias entre $22^{\circ}$ e $26^{\circ} \mathrm{C}$ no verão e $10^{\circ}$ e $15^{\circ} \mathrm{C}$ no inverno, com precipitação entre $1000 \mathrm{~mm}$ e 1500 $\mathrm{mm}$.

\subsubsection{Oceanografia}

A plataforma continental adjacente tem largura de 150 a $200 \mathrm{~km}$, com profundidades máximas variando entre 100 e $140 \mathrm{~m}$ e suave declividade de 0,5 a 1,5 m/km (Martins \& Corrêa, 1996). A antepraia é arenosa, extensa e rasa, com limite externo entre as profundidades de 7,5 e $10 \mathrm{~m}$.

O litoral do Rio Grande do Sul é influenciado por ondas vagas e ondulações, o que caracteriza um espectro direcional bimodal, interferindo um sobre o outro e com predominância ora das vagas, ora das ondulações (Wainer, 1963). Para a costa sul do Brasil, a chegada de ondulações está associada a um centro de geração de tempestades extratropicais que se localiza, em geral, no sul da Argentina. Exceto pela passagem das frentes frias de S e SE, a agitação marítima é caracterizada por ondas de média a elevada energia, com altura significativa da ordem de 1,5 $\mathrm{m}$ e período entre 7 e 9 s (Almeida et al., 1997, 1999).

A maré astronômica é semidiurna, com amplitude média de $0,30 \mathrm{~m}$, sendo que a maré meteorológica pode alcançar 1,20 m (Almeida et al., 1997). A profundidade de fechamento é estimada em 7,5 m, calculada com base em dois conjuntos de dados de ondas coletados nos anos de 1963 e 1996 no litoral norte do estado (Almeida et al., 1999). Consequentemente, o transporte e a deposição dos sedimentos ao longo da costa são, primariamente, dominados pela ação das ondas.

A distribuição das direções das correntes litorâneas ao longo de toda a costa é muito regular, tanto para SW, quanto para NE, num padrão claramente bidirecional. Segundo Nicolodi et al. (2001), entre 1996 e 1997 ocorreu um predomínio da corrente para SW com valores médios de 62,8 e $54,8 \%$, respectivamente, enquanto entre 1998 e 1999 observou-se inversão, com a corrente para NE apresentando valores de 54 e 51,2 \%. Também, pode-se afirmar que a bidirecionalidade tem componente sazonal, governada pelos parâmetros climáticos. Nos meses de outubro a março predominam as correntes para SW, e para NE nos meses de maio a agosto.

\subsection{Métodos}

0 método utilizado neste trabalho contempla o potencial da análise espaço-temporal em imagens de satélite, com a finalidade de interpretar ambientes costeiros e sua dinâmica, bem como o uso de dados de precipitação e equações para determinar a morfodinâmica do canal e variações na linha de praia.

\subsubsection{Aquisição de série temporal de imagens Lan- dsat}

A série contempla 39 imagens de 1973 a 2009, das missões Landsat 1, 2, 3, 5 e 7. Para destacar os alvos do estudo, determinaram-se as bandas de cada sensor mais adequadas. Assim, foram escolhidas as bandas $6(0,7-0,8 \mu \mathrm{m})$ para as imagens do sensor MSS; $4(0,76-0,9 \mu \mathrm{m})$ do sensor TM e; banda 8, pancromática, do sensor ETM+ $(0,52-0,90 \mu \mathrm{m})$.

\subsubsection{Georreferenciamento}

Os pontos de controle foram obtidos (GPS GARMIM PLUS III e Smartphone Nokia 5230 - GPS integrado) distribuídos ao longo de toda área no dia 20/09/2010, aplicando transformação de ajuste.

\subsubsection{Geoprocessamento}

0 geoprocessamento foi realizado com os softwares ArcGis 9.3.1. e ERDAS 9.2., com interpretação visual das imagens (método qualitativo). As equalizações dos histogramas foram realizadas de forma linear. Observando os vetores e polígonos desenvolvidos, foi possível descrever o compor- 
tamento do canal quando aberto ou fechado, bem como da morfologia submersa ao longo de 36 anos (Figs. 2A e 2B).

\subsubsection{Estudo do regime de precipitação pluviométri- CO}

Com a finalidade de analisar a influência da precipitação sobre a morfodinâmica do canal foram analisados dados médios mensais, anuais e sazonais na área do PNLP, oriundos da Agência Nacional das Águas (ANA), referente à série de 1961 - 2009, obtidos na estação meteorológica situada em -51,0571 (6570342) de longitude e -31,1481 (499950) de latitude, no município de Mostardas (RS). Devido à ausência de uma rede de pluviômetros regularmente distribuídos na área, foi aplicado o método de interpolação chamado Krigagem, com o objetivo de melhor representar espacialmente e temporalmente o comportamento da precipitação. Esse método consiste em estimativas do valor de um atributo em locais não amostrados, convertendo observações pontuais em um campo contínuo de dados (Viana, 2009). Foram estudados não somente os 48 anos de dados (1961 - 2009), como também foi analisado o período 1961-1990, que compreende a normal climatológica, inserido nessa série. A essa série de dados de precipitação foram associadas e comparadas imagens de satélite Landsat e tabela de monitoramento da abertura e fechamento do canal, elaborada por Antunes (2007).

\subsubsection{Dinâmica sedimentar}

Para determinar a capacidade de deposição sedimentar sobre a desembocadura foi utilizada a equação de Bruun (1978), e classificou-se a estabilidade do canal de acordo com Kraus (2000).

\subsubsection{Linha de praia}

A feição utilizada como geoindicador na vetorização das linhas de praia foi o limite entre areia seca e úmida (Boak \& Turner, 2005). Foram vetorizadas pixel a pixel as linhas de praia dos anos de 1987 e 2009, utilizando o método dos pontos extremos de curto termo. A fim de obter a diferença de posicionamento entre as duas linhas, os valores das coordenadas leste (UTM) dos vértices do vetor das duas linhas de praia, foram exportados para o software Excel, onde foi feita subtração entre elas. Valores positivos representam acreção, e negativos são erosão da linha de praia.

\subsubsection{Perfil altimétrico}

O perfil foi elaborado sobre a barreira IV, entre a LP e a praia oceânica, como uso de uma imagem ASTER DEM (30 m x $30 \mathrm{~m}$ ) de outubro de 2009, somada a uma imagem Landsat 7 ETM+ (2001), utilizando o software Global Mapper 11, com resultado exportado graficamente para o Excel (Fig. 3).

\section{Resultados}

O relevo da PCRGS, formado durante a construção dos sistemas deposicionais laguna-barreira, apresenta uma grande uniformidade regional. Todos os desníveis topográficos são de pequena ordem. Por esta razão, a presença de descontinuidades nas sequências deposicionais marcam facilmente impressões no terreno. Entre estas feições destacam-se, de modo geral, as suaves depressões entre as barreiras, os canais intralagunares e, na área de estudo, o truncamento da barreira IV entre a LP e a praia oceânica adjacente. Desde a formação da LP, há 7.500 anos aproximadamente (Arejano, 2006), os depósitos sedimentares da barreira IV não foram reconstruídos totalmente, apenas os depósitos do sistema praial.

0 perfil altimétrico longitudinal sobre a barreira IV (Fig. 3), com extensão de $37 \mathrm{~km}$, reproduz as oscilações de pequenas amplitudes do terreno, controladas principalmente pelo campo de dunas costeiras, que se desenvolve entre a laguna e a praia oceânica. Na metade sul do perfil ocorrem as menores cotas topográficas; portanto, o local mais favorável ao truncamento da barreira para a instalação do canal lagunar. Segundo Fitzgerald et al. (2001), esta configuração em terrenos costeiros é indício de instabilidade e de riscos a inundações. Se associados a eventos de tempestades, com marés meteorológicas incomuns, podem produzir depósitos de sobrelavagem (washover) e erosão da praia, com a possibilidade de ruptura e abertura do canal de comunicação entre a laguna e o oceano.

Com a desembocadura ativada, seja pela alta pluviosidade, seja pela ocorrência de tempestades, são estabelecidos padrões de circulação estuarina no canal lagunar, com o desenvolvimento de feições morfológicas de fundo, controladas pelas seguintes variáveis: amplitudes das marés de enchente e vazante, geometria do canal, energia das ondas e suprimento sedimentar (Fitzgerald et al., 2001). 

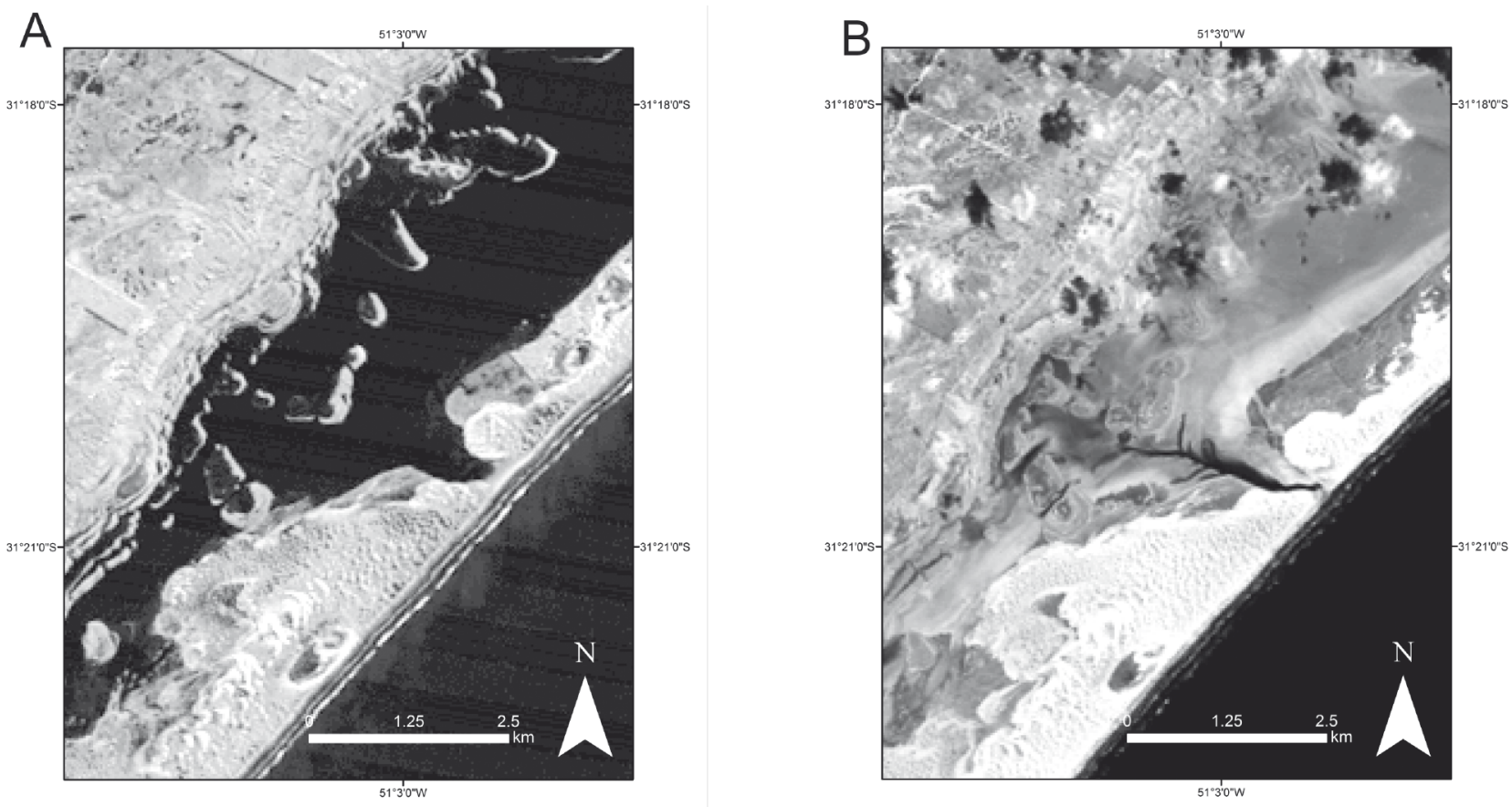

Figura 2. Imagens de satélite representando o comportamento hidrológico do volume de água na LP condicionado a configuração do canal. A) Imagem Landsat 5 TM (01/07/1997), apresentando a LP com a desembocadura fechada (laguna cheia); B) Imagem Landsat 5 TM (06/01/1997), demonstrando a LP com a desembocadura aberta (laguna vazia).

Figure 2. Satellite images representing the hydrological behavior of the water volume in the LP conditioned to the channel configuration. A) Landsat 5 TM (07/01/1997), showing the LP with a closed inlet (full lagoon); B) Landsat 5 TM (01/06/1997), showing the LP with open inlet (empty lagoon).

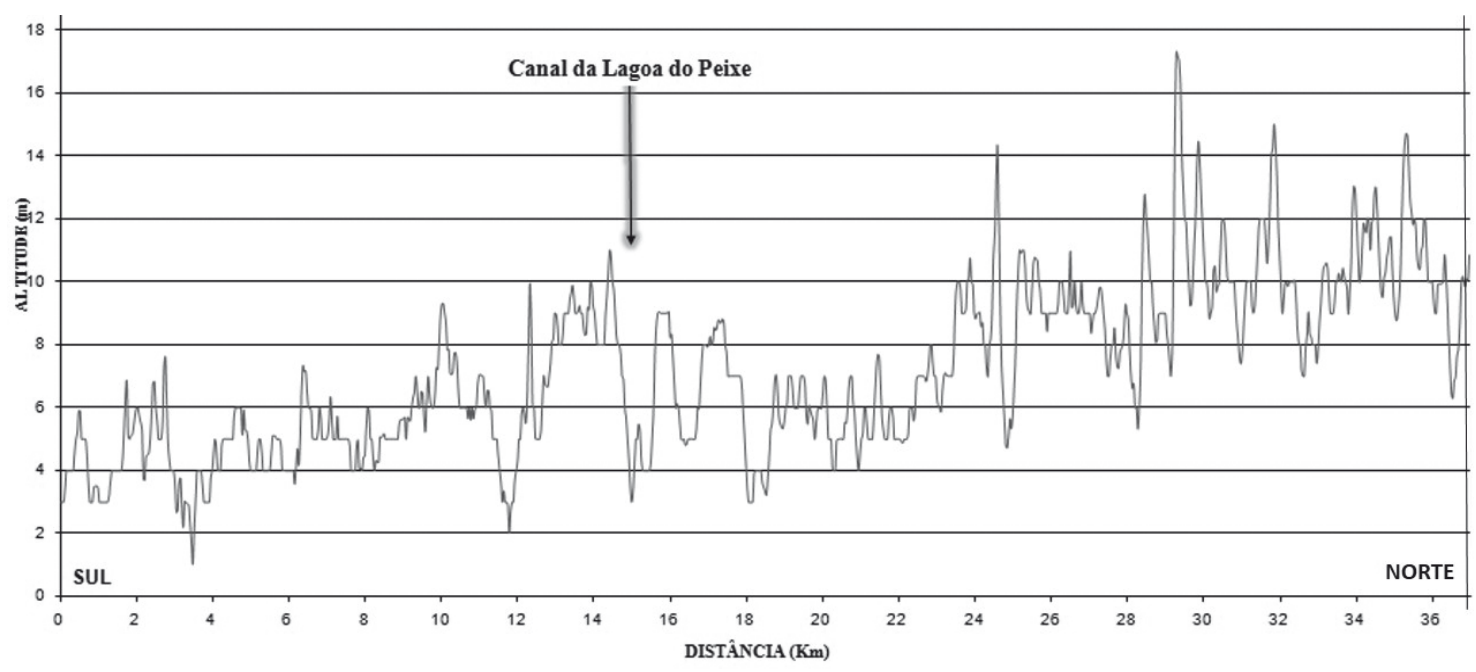

Figura 3. Perfil altimétrico da barreira IV (Fig. 1), indicando o local onde se situa a desembocadura da Lagoa do Peixe, associado a menor cota topográfica.

Figure 3. Altimetry barrier profile IV (Fig. 1), indicating the location of the LP inlet, associated with lower topographic elevation.

\subsection{Morfologia do canal}

Como é possível observar nas imagens de satélite (e.g. Fig. 7 B, C, D), o delta de maré vazante, submerso, é perceptível quando observa-se o padrão nas linhas de arrenbetação na zona de surf, apresentando lobo terminal ativo quando a desembocadura se apresenta aberta. 0 delta de vazante é destruído após o fechamento da desembocadura, geralmente nos meses subsequentes a estação de maior precipitação na área do PNLP (inverno, maior precipitação, com $117 \mathrm{~mm}$ de precipitação média, seguido pela primavera, $105 \mathrm{~mm}$ de precipitação média, segunda estação mais seca). Com o decréscimo gradual da pluviosidade nas estações seguintes (verão $107 \mathrm{~mm}$, seguida pelo outono, menor precipitação, com $92 \mathrm{~mm}$ de precipitação média), o transporte eólico é ativado, e um maior volume de areia é mobilizado na região. Parte desse volume de sedimentos chega e se deposita nas margens da desembocadura.

A esse suprimento sedimentar soma-se a 
deriva litorânea, que conduzem ao completo assoreamento do canal. A formação de pontais na desembocadura do canal lagunar evidenciam o sentido da deriva litorânea, ora com desenvolvimento sobre a margem sul, ora sobre a margem norte do canal. A direção da deriva litorânea oscila sazonalmente, confirmando a influência desta dinâmica sedimentar e da precipitação na estabilidade do canal e da embocadura, como descrito a seguir.

\subsection{Estabilidade da desembocadura}

\subsubsection{Regime de precipitação pluviométrico}

De acordo com a normal, a média anual é $1265,6 \mathrm{~mm}$, o mês de maior volume é setembro $(128,5 \mathrm{~mm})$ e o de menor é abril $(75,3 \mathrm{~mm})$. Na série completa (Fig. 4) de dados (1961 - 2008), cuja média anual é $1.358,8 \mathrm{~mm}$, os anos de maior precipitação foram 2002 (1.862,2 mm) e 2001 (1.734,6 $\mathrm{mm}$ ); os dois anos de menor precipitação foram $1988(934,7 \mathrm{~mm})$ e 1989 (956,4 mm).

Para uma avaliação consistente na relação fei- ta entre a abertura do canal e o regime de precipitação pluviométrica, é necessário associar a análise climatológica da área e considerar as intervenções antrópicas. De acordo com a diretora do PNLP, o canal é aberto artificialmente desde 1880, aproximadamente, sempre que a laguna enche e não abre naturalmente. Entretanto, uma vez aberto, fecha naturalmente nos meses que seguem, a partir de setembro, uma vez que a primavera é a segunda estação mais seca do ano na região do PNLP.

Na interpretação da série temporal de imagens, quando o corpo d'água se apresenta negro, e os bancos e pontais parcialmente e/ou totalmente submersos, a interpretação é de que a laguna se encontrava cheia (Figs. 2A e 5), com área aproximada de $700 \mathrm{~km}^{2}$ e, quando a imagem apresenta o corpo d'água cinza a laguna é qualificada como vazia (Figs. 2B e 5), com área na ordem de $400 \mathrm{~km}^{2}$. Isso se deve à maior refletância dos sedimentos de fundo da laguna no infravermelho próximo, uma vez que sua lamina d'água possui espessura média de $30 \mathrm{~cm}$.

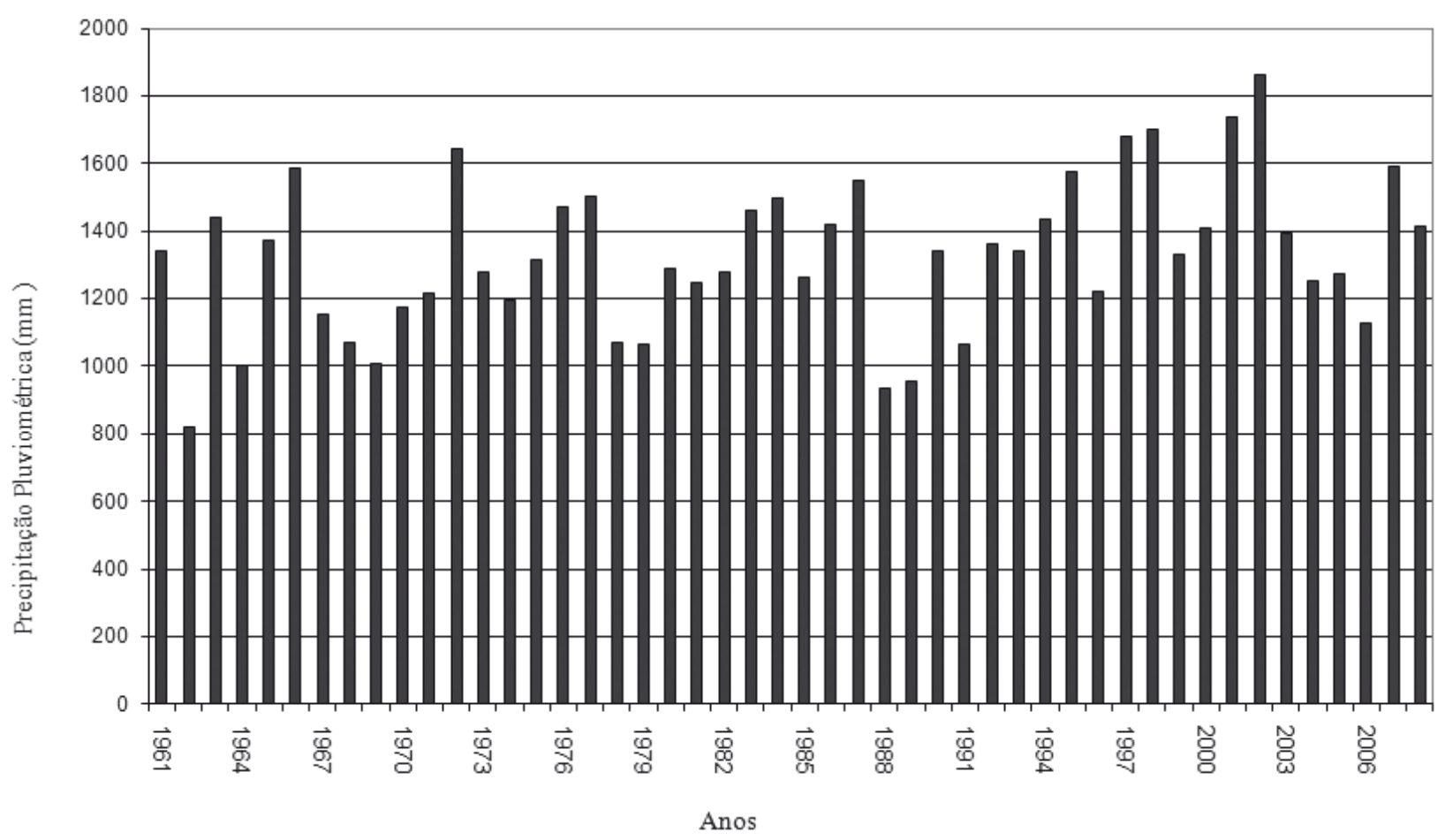

Figura 4. Valores totais anuais da precipitação pluviométrica para área do PNLP (1961 - 2008).

Figure 4. Total annual values of precipitation for the PNLP area (1961-2008).

Ao comparar as imagens selecionadas, os totais de precipitação anual e o monitoramento (Tab. 1) que acompanhou abertura e fechamento do canal por oito anos (Antunes, 2007), é possível destacar alguns aspectos importantes.

0 ano de 1997 não foi monitorado por Antunes (2007), porém, segundo comunicado pessoal da direção do PNLP em 2011, foi confirmado, extraoficialmente, que o canal abriu naturalmente, no dia 17 de julho, 40 dias antes da data da imagem selecionada, permanecendo aberto até março de 1999, pois em 1998, o total de precipitação pluviométrica também ficou acima da média da região do parque. Nos meses de junho, julho e agosto 
de 1997, os totais mensais, respectivamente são: $178,5,147,5$ e $216,9 \mathrm{~mm}$, todos acima de suas médias. Observa-se também na série temporal que existe forte relação entre as imagens que apresentam o canal aberto e os meses antecedentes de médias de maior regime pluviométrico, ou seja, se ela encher a ponto de inundar as planícies lagunares o canal pode abrir naturalmente. No monitoramento não existe relato de um ano inteiro em que o canal tenha permanecido fechado, provavelmente devido ao fato de a comunidade de pescadores abri-lo mecanicamente sempre que a LP enche. Por fim, os biênios de precipitação pluviométrica consecutivos, 1997-1998, acima das médias e também 2001-2002, o canal da LP chegou a permanecer mais de um ano aberto.

0 reservatório de água não tem capacidade para produzir vazões significativas, sem considerar as perdas por evaporação e infiltração, em razão da forte exposição da superfície de água a ação do vento, e as facilidades de perda de água no terreno arenoso que condiciona fisicamente a laguna.

\subsubsection{Dinâmica sedimentar}

A figura 6 ilustra o mecanismo de obstrução do canal da LP por assoreamento morfodinâmico
(Pope, 2000). A migração lateral do canal ocorre naturalmente, associada à deriva litorânea, pelo assoreamento de uma das margens e erosão da outra.

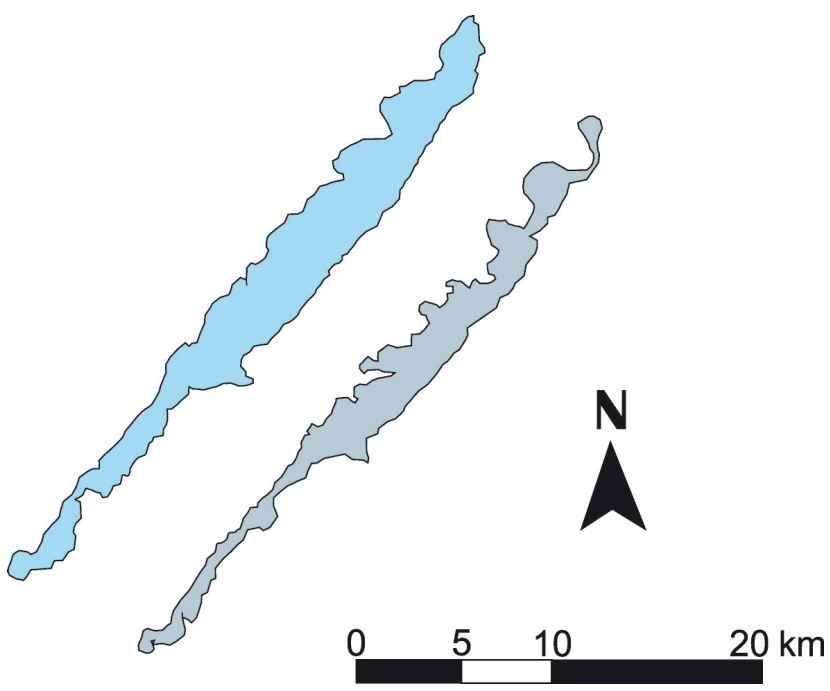

Figura 5. Comparação dos polígonos vetorizados das áreas da LP, cheia (azul) e vazia (cinza).

Figure 5. Comparison of vectorized polygons of the areas of the $L P$, full (blue) and empty (gray).

Tabela 1. Classificação da desembocadura aberta ou fechada com os períodos correspondentes (Antunes, 2007), e a respectiva condição do nível d'água da laguna: LP cheia ou LP vazia; canal aberto ou canal fechado. A coluna da direita registra a média de precipitação pluviométrica referente ao respectivo ano.

Table 1. Classification of open or closed inlet with the corresponding periods (Antunes, 2007), and its condition level of lagoon water: full LP or empty LP; open channel or closed channel. The right column records the average precipitation referring to the respective year.

\begin{tabular}{|c|c|c|c|c|c|c|c|}
\hline \multirow{2}{*}{ Ano } & \multirow{2}{*}{ Fechamento/Abertura* } & \multirow{2}{*}{ Data (imagem) } & \multirow{2}{*}{ Cheia } & \multirow{2}{*}{ Vazia } & \multicolumn{2}{|c|}{ Canal } & \multirow{2}{*}{ T. P. A.*** } \\
\hline & & & & & Fechado & Aberto & \\
\hline 1997 & Não monitorada & $27 / 08 / 1997$ & $\mathrm{x}$ & & & $\mathrm{x}$ & 1681 \\
\hline 1998 & Desembocadura aberta o ano todo & $1998^{* *}$ & & & & & 1700 \\
\hline 1999 & $\begin{array}{c}\text { Desembocadura fechou em março } \\
\text { Desembocadura aberta em julho } \\
(20 / 07 / 1999)\end{array}$ & $14 / 06 / 1999$ & $\mathrm{x}$ & & $\mathrm{x}$ & & 1331 \\
\hline 2000 & $\begin{array}{c}\text { Desembocadura fechou em janeiro }(20 / 01 / 2000) \\
\text { Desembocadura aberta em julho } \\
(04 / 07 / 2000)\end{array}$ & $19 / 08 / 2000$ & & $\mathrm{x}$ & & $\mathrm{x}$ & 1411 \\
\hline 2001 & $\begin{array}{l}\text { Desembocadura fechou em março }(23 / 03 / 2001) \\
\text { Desembocadura aberta em julho }(30 / 07 / 2001)\end{array}$ & $25 / 05 / 2001$ & $\mathrm{x}$ & & $\mathrm{x}$ & & 1734 \\
\hline 2002 & Desembocadura aberta o ano todo & $25 / 09 / 2002$ & & $\mathrm{x}$ & & $\mathrm{x}$ & 1862 \\
\hline 2003 & Desembocadura fechou em novembro $(20 / 11 / 2003)$ & $18 / 12 / 2003$ & $\mathrm{x}$ & & $\mathrm{x}$ & & 1395 \\
\hline 2004 & $\begin{array}{c}\text { Embocadura aberta em agosto } \\
(04 / 08 / 2004) \\
\text { Desembocadura fechou em dezembro }(10 / 12 / 2004)\end{array}$ & $30 / 08 / 2004$ & & $\mathrm{x}$ & & $\mathrm{x}$ & 1254 \\
\hline 2005 & Desembocadura aberta em setembro $(20 / 09 / 2005)$ & $20 / 10 / 2005$ & & $\mathrm{x}$ & & $\mathrm{x}$ & 1274 \\
\hline $\begin{array}{ll}* & \mathrm{Mc} \\
* * & \mathrm{An} \\
* * * & \text { To }\end{array}$ & $\begin{array}{l}\text { ado de Antunes (2007) } \\
\text { imagem de satélite disponível } \\
\text { Precipitação Anual }\end{array}$ & & & & & & \\
\hline
\end{tabular}


A

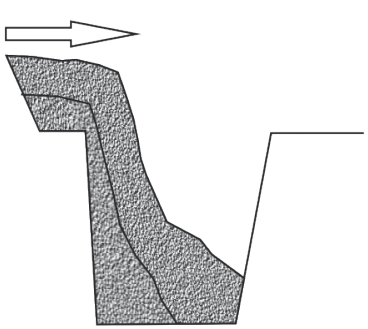

$\mathrm{B}$

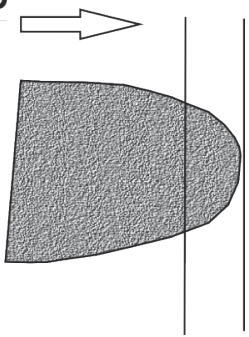

Figura 6. Mecanismo morfodinâmico de assoreamento do canal, por deposição de sedimentos associada a migração de pontais arenosos (modificado de Pope, 2000): secção em perfil de um canal mostrando o desenvolvimeto lateral de seu assoreamento (A) e em planta sobre a barreira arenosa adjacente (B).

Figure 6. Morphodynamic mechanism of silting channel, by deposition of sediment associated with migration of sandy spits (modified of Pope, 2000): profile section of a channel showing its development in an silting side (A) and in plan about the barrier sandy adjacent (B).

A deriva líquida na área de estudo tem como resultante a direção SW-NE, principalmente nos meses de inverno (Lima et al., 2001). Na transição para o verão, ocorre inversão do sentido da corrente e do transporte sedimentar, de NE para SW. É notável o maior crescimento do pontal sul, explicado pela maior capacidade de transporte de sedimentos provenientes dessa direção, principalmente durante o inverno. Este é o mecanismo que, ciclicamente, provoca o assoreamento do canal da LP (Fig. 7), favorecido também pelo baixo volume de água do corpo lagunar.

A fim de quantificar o grau de influência da deriva litorânea no mecanismo de assoreamento do canal, é necessário que se estabeleça a capacidade de deposição sedimentar sobre a desembocadura $(r)$, o qual pode ser determinado pelo prisma de maré $(P)$ e pelo volume de areia que transita em frente à desembocadura $(M)$, de acordo com equação desenvolvida por Bruun (1978): $r=P / M$.

Segundo Kraus (2000), para $r$ maior que 150 o canal é considerado estável, profundo e com baixa capacidade de migração dos bancos arenosos do delta de maré vazante. Se o valor resultante for inferior a 50, o canal é classificado como instável, com tendência a fechar, com um eficiente mecanismo de transporte de sedimentos por deriva litorânea (sand bypassing), que contribui para a formação de pontais arenosos.

A amplitude média da maré na PCRGS é da ordem de 0,30 m (e. g. Almeida et al., 1997; Toldo Jr. \& Almeida, 2003). A LP vazia possui área de $40.000 .000 \mathrm{~m}^{2}$ com prisma de maré resultante de $12.000 .000 \mathrm{~m}^{3}$. Quando a LP enche, sua área média é de $70.000 .000 \mathrm{~m}^{2}$, e seu prisma de maré atinge
$21.000 .000 \mathrm{~m}^{3}$. O valor de $M$, obtido em Lima et al. (2001), corresponde a $2.932 .000 \mathrm{~m}^{3}$, de deriva litorânea anual em frente a desembocadura, de modo que foram obtidos valores de $r$ entre 4 e 7 . A pequena oscilação deste valor controla as condições de laguna vazia e cheia, respectivamente (Fig. 5). Assim, é possível afirmar que o canal da LP é instável e intermitente, e sua forte instabilidade é em decorrência da intensa deriva litorânea na PCRGS, que possibilita a formação de pontais na sua desembocadura, também favorecidos pelo fraco prisma de maré.

\subsection{Linha de praia}

De acordo com Boak \& Turner (2005), para estudos significativos de mudanças na linha de praia, é adequado utilizar série de dados de 10 a 20 anos no mínimo. Com a finalidade de obter uma interpretação de qualidade, é aconselhável analisar esse comportamento em pequenos trechos da praia, pois o resultado não corresponderá genuinamente às mudanças ao longo de uma praia inteira.

Os geoindicadores de linha de praia podem ser escolhidos por uma morfologia costeira visualmente identificável ou por dados numéricos específicos. Existem 45 exemplos de geoindicadores da linha de praia na literatura, sendo os mais utilizados o limite entre a praia seca e úmida e posição de máximo espraiamento da onda e linha de água. A maior qualidade desses geoindicadores é serem lateralmente contínuos, ou seja, apresentarem-se sem interrupções ao longo de toda praia (Pajak \& Leatherman, 2002).

Com o objetivo de determinar a localização da linha de praia adjacente ao PNLP, foi utilizado o limite entre a praia seca e úmida, que segundo muitos autores (e.g. Dolan, et al., 1978, 1980; Overton et al., 1999) corresponde ao limite máximo de espraiamento da onda em condições de preamar. Os recursos utilizados foram imagens Landsat 5 TM, com erro espacial recorrente de $30 \mathrm{~m}$. Boak \& Turner (2005) destacaram como vantagem dessa metodologia o monitoramento por um longo período, devido a acessibilidade as imagens de sensoriamento remoto na atualidade.

Na aplicação do método de pontos extremos, com a finalidade de averiguar a variação na linha de praia adjacente ao PNLP, foi utilizada a tendência de curto prazo (23 anos), com imagens de 1987 a 2009, com imagens do mesmo sensor (mesmo erro espacial), entre as latitudes de $477800 \mathrm{~N} \mathrm{a}$ $525350 \mathrm{~N}$. A latitude de $496820 \mathrm{~N}$ e a longitude de 6531000 E marcam, aproximadamente, a região 

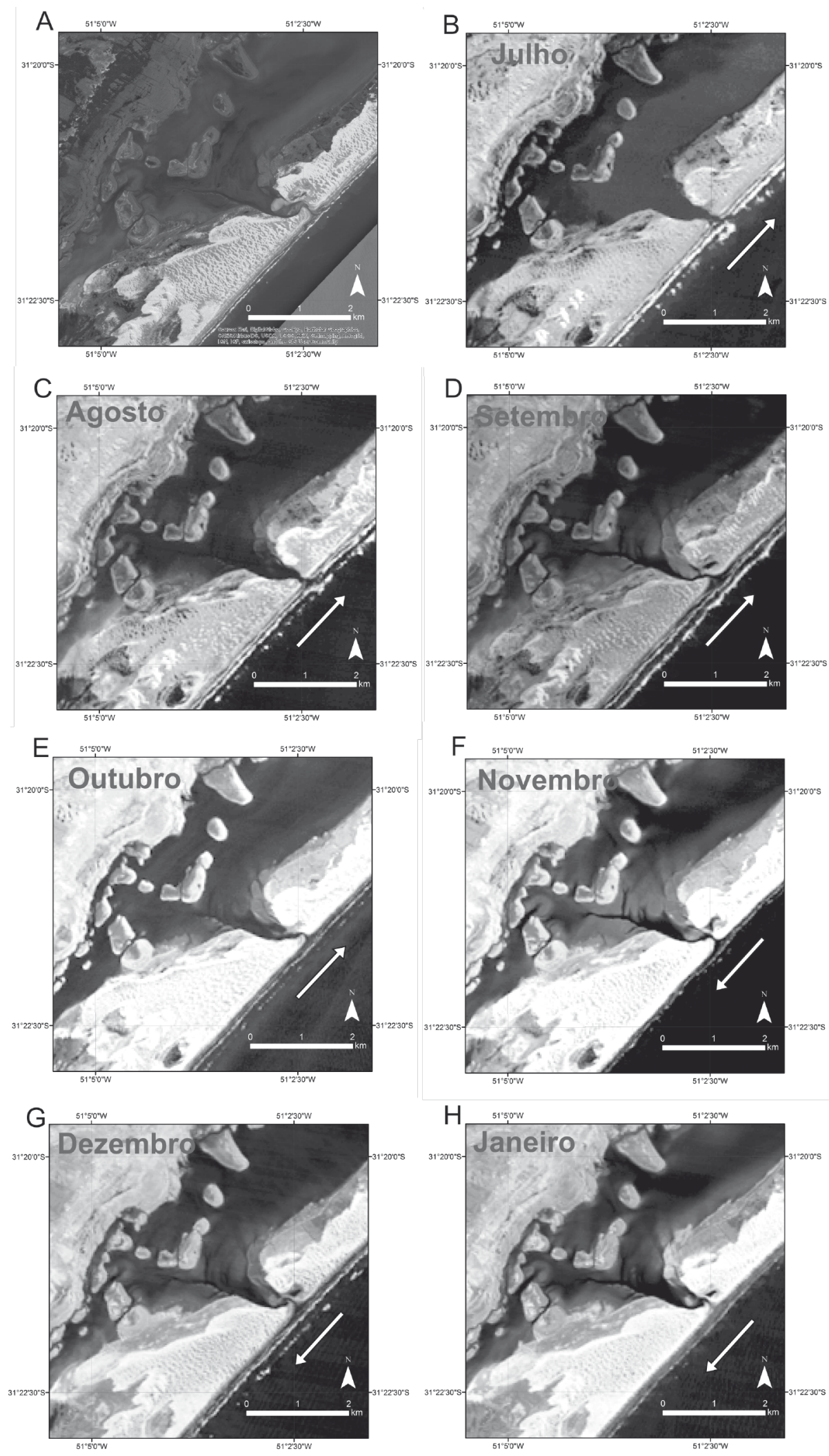

Figura 7. Sequência de imagens Landsat 5 TM, banda 4, ilustrando o desenvolvimento dos pontais sobre a desembocadura e vetores brancos indicando o sentido preferencial das correntes nos respectivos meses. A) Imagem do canal da Lagoa do Peixe no Google Earth; B, C, D e E) crescimento do pontal para NE, concordante com a direção preferencial da deriva litorânea SW-NE nos meses de inverno e início da primavera em Julho 2001, Agosto 2000, Setembro 2008, Outubro 2001; F, G e H) crescimento do pontal para SW, na transição para os meses de verão, em Novembro 2004, Dezembro 2009 e Janeiro 2009, respectivamente. Figure 7. Landsat 5 TM band 4 image sequence, illustrating the development of spits on the inlet and white vectors indicating the preferred direction of the currents in the respective months. A) LP channel image on Google Earth; B, $C, D$ and E) pontal growth for NE direction, consistent with the preferred direction of the SW-NE littoral drift in the winter months and early spring in July 2001, August 2000, September 2008, October 2001; F, G and H) pontal growth for SW, in the transition to the summer months, in November 2004, December 2009 and January 2009, respectively. 
de transição entre estes processos, com tendências opostas de mobilidade da linha de praia, sem o controle da amplitude da maré, o qual se constitui em erro mensurável de pequena escala (em razão de seu pequeno valor no RS). Ainda assim, a análise comparativa entre os resultados obtidos, com diferentes metodologias, indica o mesmo comportamento de mobilidade da linha de praia no litoral médio do estado. Toldo Jr. et al. (1999, 2006a) definem que a metade sul da praia oceânica do PNLP encontra-se em processo de erosão, e a metade norte em acreção. A figura 8 mostra o resultado do método proposto nesse trabalho: o gráfico apresenta tendência a alargamento na área de inflexão e campo de dunas do PNLP e transição a comportamento erosivo a partir da área próxima ao canal lagunar, e em direção ao sul do parque.

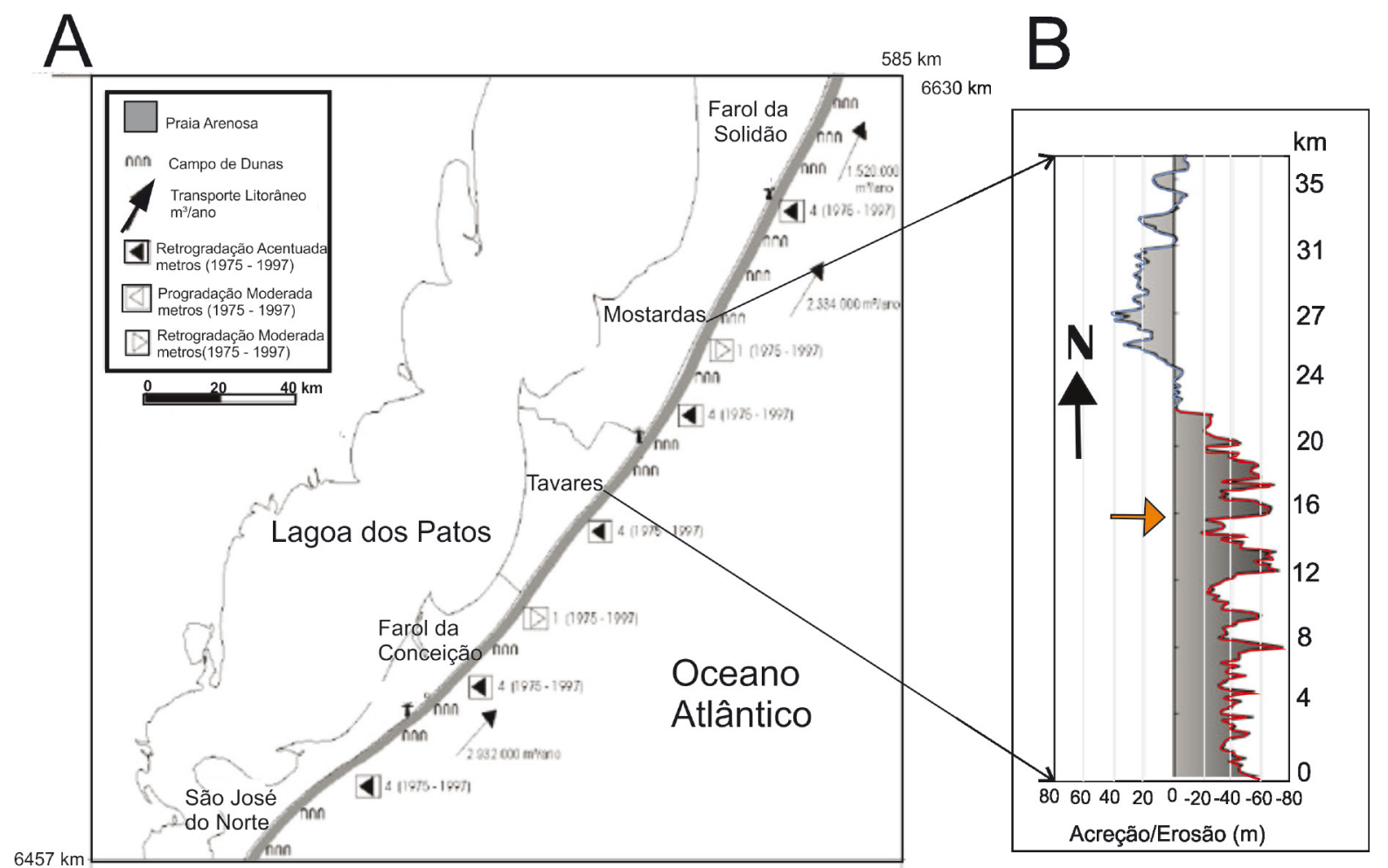

$369 \mathrm{~km}$

Figura 8. Comparação entre os resultados encontrados por Toldo Jr. et al. (2005) e o presente estudo, as setas indicam a área de estudo. A) resultados da análise temporal de 22 anos (1975-1999) de Toldo Jr. et al. (2005) das tendências de mobilidade da linha de praia para o litoral médio do estado do Rio Grande do Sul; B) resultado da mobilidade da linha de praia no presente estudo pelo método dos pontos extremos indicando a localização do canal no perfil (seta laranja), com erosão em vermelho e acreção em azul.

Figure 8. Comparison of the results found by Toldo Jr. et al. (2005) and the present study, the arrows indicate the study area. A) results of temporal analysis of 22 years (1975-1999) of Toldo Jr. et al. (2005) of mobility trends from the shoreline to the average coast of Rio Grande do Sul state; B) a result of mobility of the shoreline in the present study by the method of end points indicating the inletl profile location (orange arrow), with erosion in red and accretion in blue.

\section{Discussão dos resultados}

A integração do geoprocessamento aplicado à interpretação morfodinâmica e geomorfológica em ambientes costeiros se apresentou bastante eficiente. Os resultados obtidos na análise multitemporal de imagens Landsat são coerentes quando comparadas às classificações obtidas pelas aplicações de outros métodos quantitativos, muitos deles envolvendo processos de medida direta. Serpa (2013) descreve a relevância ambiental dos sangradouros e canais de drenagem similares ao da LP. Para o autor, o ciclo morfodinâmico dessas feições explica como o excedente hídrico na região costeira é extravasado e, como a interferência nesses ciclos naturais podem trazer benefícios e malefícios, não só para as cidades litorâneas, como também para a própria dinâmica natural de todo ambiente costeiro. Um aspecto importante a ser observado é como a erosão de sedimentos, realizada por esses escoadouros, podem interferir no balanço sedimentar ao longo da linha de praia.

Na série de imagens Landsat interpretadas nesse estudo, foram identificadas a formação de deltas, tanto de enchente, emerso, quanto de vazante, submerso. 0 delta de vazante é destruído 
quando a desembocadura fecha (primavera), após a estação de maior precipitação (inverno) no PNLP. Deltas de vazante bem desenvolvidos são indício de costa dominada por marés, porém se pequenos, ou submersos, evidenciam uma costa de meso a micromarés, dominadas por ondas (Hayes, 1975). Os deltas na LP são pouco desenvolvidos, tipico de uma costa dominada por ondas, de acordo com classificação de Hayes (1975).

Para Haines (2008), uma laguna intermitente possui um ciclo de atividades que passa por três estágios hidrodinâmicos diferentes, relacionados à morfodinâmica de seu canal: canal aberto, assoreando e fechado. Esse ciclo inicia com a disponibilidade de sedimentos no sistema praial, depositados na desembocadura do canal pelas correntes litorâneas. Em casos de escassez de chuva, a propria condição climática permite que a areia da praia seque, fornecendo sedimentos também pelo transporte eólico. No canal da LP esse processo desenvolve pontais, com a mesma orientação da corrente litorânea preponderante, estando o assoreamento do canal associado à construção desses pontais. A partir das correntes litorâneas predominantes de SW (inverno e primavera) ocorre a migração do pontal a partir da margem sul e consequente erosão da margem norte do canal, sendo este mecanismo responsável pela sua migração lateral em direção norte. Com a aproximação do verão e inversão da direção da corrente, a deposição dos sedimentos ocorre preferencialmente na margem norte, iniciando a formação do segundo pontal e promovendo a erosão da margem oposta. Na continuidade do processo, quando ambos os pontais se encontram, geralmente nos meses de verão, ocorre a completa obstrução do canal pelos depósitos do sistema praial (Fig. 7).

0 mecanismo supracitado reduz a seção transversal mínima (Fitzgerald, 1996), alongando o comprimento do canal, principalmente devido ao meandramento forçado pela migração dos pontais em direções opostas, processo fundamental para oclusão do canal. Portanto, a instabilidade de sua desembocadura está associada aos depósitos do sistema praial, condicionados a influência da dinâmica sedimentar pela deriva litorânea, que é intensa no litoral do RS (Lima et al., 2001). A precipitação anômala é um fator decisivo na abertura natural do canal da LP, uma vez que o local onde o canal se instalou é um dos pontos de menores cotas no perfil altimétrico (Fig. 3), o que facilita a inundação e rompimento da barreira arenosa adjacente. Para ocorrer o rompimento desses depósitos são necessários eventos de tempestade, principalmente se associados a períodos de pre- cipitação intensa e de longa duração, aumentando o gradiente da pressão horizontal da água armazenada no corpo lagunar sobre o canal principal (Mehta, 1996).

O estudo da precipitação sobre o PNLP permitiu relacionar os totais de precipitação ao monitoramento realizado por Antunes (2007). Essa comparação é esclarecedora, uma vez que confirma a relação entre os volumes de chuva e os períodos em que o canal se encontrava aberto e fechado, com o corpo lagunar cheio e vazio. De acordo com Silva (2009) a Barra do Camacho (Santa Catarina) abriu naturalmente em 1978, após longo período de precipitação acima da média. Haines (2008) afirmou que para ocorrer a abertura de desembocaduras de lagunas intermitentes é necessária elevação do nível d'água, que geralmente ocorre após uma precipitação acima da média, iniciando com um pequeno canal sobre o berma, que irá evoluir para o rompimento total da barreira, devido a diferença entre os níveis de água da lagoa/laguna e o mar adjacente.

No inverno a área de estudo é dominada por ventos de SSW, SW e WSW, maiores responsáveis pelas tempestades registradas, sendo este o período de maiores modificações no perfil praial na PCRGS (Barletta, 2000). Haines (2008) afirmou que os ICOLLs na África do Sul e México passam a maior parte do tempo naturalmente fechados, em períodos de pouca precipitação, abrindo somente na estação de chuvas, como é o caso do canal da LP, mesmo que ele seja aberto mecanicamente. No canal da LP o rompimento natural da barreira arenosa existente sobre a desembocadura no perfil praial foi registrado em um único momento (julho de 1997, 147 mm de precipitação no mês), e da mesma forma que ocorre quando é removida mecanicamente, acaba assoreando, lentamente, nos meses que seguem. De acordo com Haines (2008) canais que não se fecham logo após o rompimento da barreira arenosa são assoreados por sedimentos transportados pelas correntes costeiras.

De acordo com classificação de Bruun (1978), o canal da LP foi classificado como instável, com tendência a fechar, favorecido pelo fraco prisma de maré e alto volume de sedimentos que transitam pela deriva litorânea em frente a sua desembocadura, no oceano Atlântico. Segundo Nicolodi et al. (2001), a distribuição das direções das correntes litorâneas ao longo da PCRGS é muito regular, tanto para SW, quanto para NE, em um padrão claramente bidirecional, acompanhando o desenvolvimento dos pontais que fecham a desembocadura do canal da LP. A deriva litorânea decorrente de ondas do quadrante S-SW na PCRGS gera correntes com 
grande capacidade de arraste, responsáveis por $30 \%$ do transporte total, permitindo a associar ao início do desenvolvimento do pontal na margem sul na desembocadura do canal da LP no inverno. As de maior frequência, N-NE, produzem pequena deriva total, 2\% (Lima et al., 2001), e ocorrem preferencialmente na primavera e verão, quando é parcialmente erodido o pontal sul na desembocadura, enquanto o pontal norte inicia seu desenvolvimento, culminando no fechamento.

Na aplicação do método de pontos extremos (1987-2009) para determinar a variação na linha de praia adjacente ao PNLP, foi utilizada a tendência de curto prazo (23 anos). Os pontos de coordenadas 496820 N 6531000 E marcam, aproximadamente, a região de transição entre os processos de erosão e acreção na linha de praia estudada (acreção ao norte, erosão ao sul desse local, não considerando a amplitude de maré). A amplitude de maré se constitui em um erro mensurável de pequena escala (em razão de seu pequeno valor no Rio Grande do Sul que possui um regime de micromaré). 0 método qualitativo de interpretação da linha praia por pontos extremos em imagens de satélite, aqui utilizado, delimitado pela feição marca d'água entre a areia seca e a úmida, apresentou tendências similares quando comparados aos resultados obtidos em outros trabalhos que aplicaram métodos distintos (e.g. Toldo Jr. et al., 1999; Toldo Jr. \& Almeida 2003).

Entre os trabalhos de monitoramento de linha de praia que aplicaram métodos de medidas direta na PCRGS, podemos citar como exemplos Toldo Jr. et al. (1999), Esteves et al. (2003) e Toldo Jr. \& Almeida (2003). No monitoramento da linha de praia com DGPS, realizado por Toldo Jr. et al. (1999, 2006a) e Toldo Jr. \& Almeida (2003), ao longo dos $615 \mathrm{~km}$ da costa do Rio Grande do Sul, foram encontradas uma extensão de $442 \mathrm{~km}$ em processo erosivo e $173 \mathrm{~km}$ de acreção, no período compreendido entre 1975-1997. A retração e o avanço constatados são atribuídos às diferenças nas taxas de deriva litorânea ao longo do litoral e orientação da linha de costa (Toldo Jr. et al., 2006b).

Os resultados do mapeamento do deslocamento da linha de praia apresentam correspondência com o comportamento do perfil altimétrico realizado sobre a barreira IV (Fig. 3). As maiores cotas no terreno, entre a laguna e a praia oceânica, foram registradas no trecho de praia em acreção, e as menores cotas ao longo da praia sob o processo de erosão. Portanto, tanto as menores cotas topográficas, quanto retração da linha de praia podem atuar no controle do local de instalação do canal lagunar.

\section{Conclusões}

O estudo permitiu determinar que o canal da LP é uma feição natural que apresenta um traçado instável e feições deltaicas padrão, estabelecido numa costa dominada por ondas. As características observadas classificam o canal da LP como um canal de maré, com forte influência na sua constituição do prisma de maré e no volume de sedimentos que transitam próximo à sua desembocadura pela deriva litorânea. Sua oclusão ocorre pelo desenvolvimento de pontais, que acompanham as correntes litorâneas preferenciais, distribuídas sazonalmente em um padrão bidirecional, ora de S SW (inverno), ora de NE (primavera e verão). 0 encontro dos dois pontais, um que se desenvolve na margem sul, e outro que se forma na margem norte da desembocadura, marcam o fim do processo de assoreamento morfodinâmico do canal da LP. A abertura do canal ocorre quase sempre de forma mecânica, quando a LP fica cheia demais, com apoio da prefeitura do município de Tavares, em favorecimento da colônia de pescadores. Sua abertura permite a troca de nutrientes necessários a melhor reprodução e sobrevivência dos peixes e camarões que ali habitam e servem de fonte de renda a comunidade. Essa abertura artificial ainda é motivo de conflito entre a administração do PNLP e a comunidade de pescadores. A inexistência de dados de monitoramento de longo prazo, pela administração do parque, ou até mesmo por moradores, dificultou saber quando o canal abriu sozinho no período estudado, com exceção do ano de 1997, que foi testemunhado o rompimento natural da barreira, devido a excedente de precipitação.

A mobilidade da linha de praia adjacente ao canal da LP, bem como a altimetria do terreno sobre a barreira IV, apresentam-se como importantes variáveis controladoras do local de instalação do canal da LP, no setor sul do PNLP. 0 resultado do estudo de curto prazo indicou que a porção da linha de praia que está localizada ao norte do canal encontra-se em processo de acreção, evidenciado por extenso campo de dunas presente. Já a porção ao sul do canal da LP encontra-se em processo erosivo.

Seria importante, em estudos futuros, utilizar os dados aqui apresentados sobre a morfodinâmica do canal para elaborar um plano de manejo de abertura mecânica do canal, no qual se tentasse projetar, pela estimativa de precipitação nos meses de outono e inverno, quando ele abriria naturalmente, evitando assim a abertura forçada quando desnecessário. 
Agradecimentos Ao CNPq agradecemos o suporte da bolsa durante o mestrado da autora Venisse Schossler, que possibilitou o desenvolvimento do presente trabalho.

\section{Referências}

Almeida, L.E.S.B., Rosauro, N.M.L. \& Toldo Jr., E.E. 1997. Análise preliminar das marés na barra do Rio Tramandaí, RS. In: SIMPÓSIO BRASILEIRO DE RECURSOS HÍDRICOS, 12, Vitória, ES. Anais... Belo Horizonte, ABRH, v.1, p.560-566.

Almeida, L.E.S.B., Rosauro, N.L., Toldo Jr., E.E. \& Gruber, N.L.S. 1999. Avaliação da profundidade de fechamento para o litoral norte do Rio Grande do Sul. In: SIMPÓSIO BRASILEIRO DE RECURSOS HÍDRICOS, 13, 1999, Belo Horizonte. Anais...Belo Horizonte, ABRH, CD-ROM, 8p.

Antunes, M.L.F. 2007. A Pesca do Camarão-Rosa Farfantepenaeus paulensis na Lagoa do Peixe (RS): Análise Quantitativa de Recrutamento, Crescimento e Mortalidade com Vistas ao Gerenciamento Pesqueiro - Fase Juvenil. Porto Alegre, 178p. Tese de Doutorado, Programa de Pós-Graduação em Zoologia, Faculdade de Biociências, Pontifícia Universidade Católica do Rio Grande do Sul.

Arejano, T.B. 2006. Geologia e evolução holocênica do sistema lagunar da "Lagoa do Peixe", litoral médio do Rio Grande do Sul, Brasil. Porto Alegre, 94p. Tese de Doutorado, Programa de Pós-Graduação em Geociências, Instituto de Geociências, Universidade Federal do Rio Grande do Sul.

Barletta, R.C. 2000. Efeitos da interação oceano-atmosfera sobre a morfodinâmica das praias do litoral central do Rio Grande do Sul, Brasil. Rio Grande, 160 p. Dissertação de Mestrado. Programa de Pós-Graduação em Oceanografia, Física e Química Geológica, Fundação Universidade do Rio Grande.

Boak, E.H. \& Turner, I.L. 2005. Shoreline definition and detection: a review. Journal of Coastal Research, 21(4): 688-703.

Bruun, P. 1962. Sea level rise as a cause of shore erosion. In: AMERICAN SOCIETY OF CIVIL ENGENEERS, WATERWAYS AND HARBOUR DIVISION. Proceedings..., v.88, p. 117-130.

Bruun, P. 1978. Stability of Tidal Inlets. Amsterdan, Elsevier Scientific Publishers, 509p.

Coastal Engineering Manual. 2002.Washington, D.C., Army Corps of Engineers United States of America, 1100p.

Dillenburg, S.R., Roy, P.S., Cowell, P.J. \& Tomazelli, L.J. 2000. Influence of antecedent topography on coastal evolution as tested by the Shoreface Translation-Barrier Model (STM). Journal of Coastal Research, 16(1): 71-81.

Dolan, R.; Hayden, B.P., \& Heywood, J. 1978. A new photogrammetric method for determining shoreline erosion. Coastal Engineering, 2(1): 21-39.

Dolan, R.; Hayden, B.P., May, P., \& May, S.K. 1980. The reliability of shoreline change measurements from aerial photographs. Shore and Beach, 48(4), 22-29.

Esteves, L.S., Toldo Jr., E.E. \& Dillenburg, S.R. 2003 Influência na mobilidade praial nas estimativas das taxas de variação da linha de costa. In: IX CONGRESSO BRASILEIRO DE ESTUDOS DO QUATERNÁRIO, 9, 2003, Recife. Anais...Recife, CD-ROM, 3p.

Fitzgerald, D.M. 1996. Geomorphic variability and morphologic and sedimentologic controls on tidal inlets. Journal of Coastal Research, 23(1): 47-71.

Fitzgerald, D.M., Kraus, N.C. \& Hands, E.B. 2001. Natural mechanisms of sediment bypassing at tidal inlets. Vicksburg, ERDC/CHL CHETN-IV-30, U.S. Army Engineer Research and Development Center, 10p. (Internal Report).

Gruber, N.L.S. 2002. A antepraia na região de Tramandaí, RS. Porto Alegre, 221p. Tese de Doutorado, Programa de Pós-Graduação em Geociências, Instituto de Geociências, Universidade Federal do Rio Grande do Sul.

Haines, P.E. 2008. ICOLL management - strategies for a sustainable future. BMT WBM Pty Ltd, Broadmeadow, NSW, $98 \mathrm{p}$.

Hayes, M.O. 1975. Morphology of sand accumulations in estuaries. In: Cronic, L.E. (Ed.), Estuarine Research. New York, Academic Press, v. 2, p. 1-27.

Jain, M., Mehta, A.J., Kreeke, J. Van de \& Combrowski, M.R. 2004. Observations on the stability St. Andrew Bay inlets in Florida. Journal of Coastal Research, 3(20): 913-919.

Knak, R.B. (org). 1998. Relatório técnico final. Projeto de caracterizaçao ambiental do Parque Nacional da Lagoa do Peixe. Rio Grande: FURG, Departamento de Oceanografia, Laboratório de Ecologia de Sistemas, 327 p.

Kraus, N.C. 2000. Reservoir model of ebb -tidal shoal evolution and sand by passing. Journal of Waterway, Port, Coastal and Ocean Engineering, 126(3): 305313.

Lima, S.F., Toldo Jr., E.E. \& Almeida, L.E.S.B. 2001. Estimativa da capacidade do transporte longitudinal de sedimentos a partir de dados de ondas para a costa do Rio Grande do Sul. Pesquisas, 28(2): 99-107.

Martins, L.R. \& Corrêa, I.C.S. 1996. Morphology and sedimentology of southwest Atlantic coastal zone and continental shelf from Cabo Frio (Brazil) to Peninsula Valdes (Argentina). Porto Alegre, IOC-UNESCO / MCT / CPRM Publication, 74p. (Internal Report).

Mehta, A.J. 1996. A perspective on process related research needs for sandy inlets. Journal of Coastal Research, SI (23): 3-21.

Nicolodi, J.L., Toldo Jr., E.E. \& Gruber, N.L.S. 2001. Frequência e sazonalidade das marés meteorológicas no Litoral Norte do Rio Grande do Sul. In: CONGRESSO DA ASSOCIAÇÃO BRASILEIRA DE ESTUDOS DO QUATERNÁRIO, 8, 2001, Imbé. Anais... Imbé, ABEQUA, V.1, p.212-214.

Nicolodi, J.L., Siegle, E., Rechden, R.C. \& Corrêa, I.C.S. 2002. Análise sedimentológica do pós-praia no Rio Grande do Sul. In: Martins, L.R., Toldo Jr., E.E. \& Dillenburg, S.R. (Eds). Erosão Costeira: Causas, Análise 
de Risco e sua Relação com a Gênese de Depósitos Minerais, Porto Alegre, Centro de Estudos de Geologia Costeira e Oceânica, $3 p$.

Nimer, E. 1977. Clima. In: Geografia do Brasil - Região Sul. Rio de Janeiro: IBGE/SERGRAF, v.5, p. 35-79.

Overton, M.F., Grenier, R.R., Judge, E.K., \& Fisher, J.S. 1999. Identification and analysis of coastal erosion hazard areas: Dare and Brunswick Counties, North Carolina. Journal of Coastal Research, Special Issue, 28, p. 69-84.

Pajak, M.J. \& Leatherman, S. 2002. The High Water Line as Shoreline Indicator. Journal of Coastal Research, 18(2): 329-337.

Pope, J. 2000. Where and why inlet channels shoal: conceptual geomorphic framework. Vicksburg, ERDC/ CHL CHETN-IV-30, U.S. Army Engineer Research and Development Center, 10p. (Internal Report).

Serpa, C.G. 2013. Morfodinâmica praial relacionada a presença de corpos de água intermitentes em duas praias da costa do Rio Grande do Sul, Brasil. Rio Grande, 131p. Tese de Doutorado, Programa de Pós-Graduação em Oceanografia, Física e Química Geológica, Fundação Universidade do Rio Grande.

Silva, G.V. 2009. Analise da Estabilidade Quanto a Posição das Desembocaduras do Rio Araranguá, da Barra do Camacho e do Rio da Madre, Litoral Sul e Centro do Estado de Santa Catarina. Itajaí, 78p. Monografia de Conclusão de Curso, Curso de Oceanologia, Universidade do Vale do Itajaí.

Toldo Jr., E.E., Almeida, L.E.S.B., Barros, C. \& Martins, L.R. 1999. Retreat of the Rio Grande do Sul Coastal Zone, Brazil. In: Martins, L.R. \& Santana, C.I. (Eds.). Non-Living Resources of the Southern Brazilian Coastal Zone and Continental Margin. Porto Alegre, Editora UFRGS, p.62-68.

Manuscrito 571

Editoras: Marina Bento Soares \& Maria do Carmo Lima e Cunha.
Toldo Jr., E.E. \& Almeida, L.E.S.B. 2003. A Linha d'água como Indicadora da Posição da Linha de Praia. In: CONGRESSO BRASILEIRO DE ESTUDOS DO QUATERNÁRIO, 9, Recife. Anais...Recife, ABEQUA, CD-ROM, 3p.

Toldo Jr., E.E., Almeida, L.E.S.B., Nicolodi, J.L. \& Martins, L.R. 2005. Retração e Progradação da Zona Costeira do Estado Rio Grande do Sul. Gravel, 3: 31-38.

Toldo Jr., E.E., Almeida, L.E.S.B., Nicolodi, J.L., Absalonsen, L. \& Gruber, N.L.S. 2006a. O Controle da Deriva Litorânea no Desenvolvimento do Campo de Dunas e da Antepraia no Litoral Médio do Rio Grande do Sul. Pesquisa em Geociências, 33(2): 35-42.

Toldo Jr., E.E., Nicolodi, J.L., Almeida, L.E.S.B., Corrêa, I.C.S. \& Esteves, L.S. 2006b. Coastal Dunes and Shoreface Width as a Function of Longshore Transport. Journal of Coastal Research, Proceedings of the 8th International Coastal Symposium, SI39: 390-394.

Truccolo, E.C. 1993. Caracterização química da Lagoa do Peixe. Rio Grande, 51p. Monografia de Conclusão de Curso em Oceanografia, Fundação Universidade de Rio Grande.

Viana, D.R. 2009. Comportamento espaço-temporal da precipitação na Região Sul do Brasil utilizando dados TRMM e SRTM. São José dos Campos,164 p. Dissertação de Mestrado em Sensoriamento Remoto, Instituto Nacional de Pesquisas Espaciais.

Villwock, J.A. \& Tomazelli, L.J. 1995. Geologia Costeira do Rio Grande do Sul. Porto Alegre, Notas Técnicas: CECO, Instituto de Geociências Universidade Federal do Rio Grande do Sul,, 8, 45p.

Wainer, I.J. 1963. Análise e Previsão das Alturas de Onda em Tramandaí. Porto Alegre, Instituto de Pesquisas Hidráulicas, UFRGS, 30p. (Relatório interno). 
